\title{
Reflexões sobre o ensino de um ofício
}

\author{
Flávia Costa Itiberê da Cunha ${ }^{1}$; Rodrigo Mateus Pereira ${ }^{2}$
}

\section{Resumo}

O objetivo deste estudo é refletir a respeito do ensino de disciplinas de caráter essencialmente prático em ambiente universitário, investigando articulações com algumas abordagens pedagógicas e, ao mesmo tempo, traçando um paralelo com práticas de adestramento e experimentação existentes no método utilizado pelos autores em sala de aula. Concluiu-se que apesar da aparente oposição entre as abordagens no âmbito teórico, na prática se percebe uma complementaridade entre elas, tornando-as na verdade etapas, que se mostram igualmente necessárias na construção de uma formação acadêmica completa.

Palavras Chave: Ensino; Aprendizagem; Ofício; Behaviorismo; Nova escola.

\section{Introdução}

Esse texto tem como base a vivência docente dos autores no ensino de disciplinas de caráter exclusivamente prático e que envolvem profundamente a transmissão do conhecimento tácito em áreas específicas - conhecimento este que o indivíduo adquire ao longo da vida, pela experiência e dificilmente é formalizado ou explicado a outra pessoa, pois é subjetivo e inerente às habilidades individuais. Nestas áreas existe uma "tradição" de ensino/aprendizagem que, a princípio, não se amolda às teorias pedagógicas dos séculos XIX e XX. Ainda que esse encaixe não seja necessário, aqui se busca embasamento numa tentativa de subsidiar essa educação dentro da universidade, realidades que esses ofícios alcançam no século XXI. Para isso, duas teorias, que parecem adequar-se à proposta, são apresentadas e avaliadas sincronicamente à experiência em sala de aula.

Para a compreensão do que aqui é chamado de ofício, utiliza-se a recapitulação histórica de Dubar (2005) onde, na Idade Média a partir do século XI, as artes liberais e as artes mecânicas, representadas respectivamente pelos artistas/intelectuais e pelos artesãos, faziam parte da mesma organização corporativa. Assim, ambas professavam uma arte. Com a consolidação das universidades, as artes liberais e mecânicas se dissociaram, levando a uma oposição entre profissões: derivada das artes liberais, ensinadas na universidade, versus os ofícios: oriundos das artes mecânicas. Ou seja, os ofícios estão diretamente relacionados com

\footnotetext{
${ }^{1}$ UNIANDRADE, Professora no Curso Design de Moda. Email: flaviaitibere@gmail.com.

${ }^{2}$ UFPR, Professor do Curso de Tecnologia em Luteria. Email: rodmateus@ hotmail.com.
} 
o "fazer", onde a teoria e prática se imbricam e constituem o artesão sem a obrigação do ensino formal. Souza Neto (2005), numa visão mais contemporânea, considera que um ofício acontece na oficina, onde acontecem os rituais do trabalho e onde o artesão abriga seu arsenal de objetos e ferramentas.

O exercício de qualquer ofício, nesse sentido, pressupõe que o seu realizador domine os processos que lhe são inerentes e seja capaz de executá-los de maneira a observar como cada momento, cada detalhe por diminuto que seja, cada gesto ainda que automático, resulta de uma unidade em que os fragmentos só justificam sua existência por fazerem parte do todo (SOUZA NETO, 2005 p.250).

Objetiva-se assim por uma reflexão a respeito do ensino de um ofício em ambiente universitário, articulando o behaviorismo e teorias pedagógicas alternativas com a prática de "adestramento" e livre experimentação no processo de aprendizagem. O sentido de adestramento aqui é o conceituado por Mauss (2003) na educação para a construção do movimento, que constrói o corpo e a técnica corporal. O autor compara a obtenção de técnicas com aquisição de rendimento, que conseguinte se relaciona com destreza, designada como sendo "a adaptação de movimentos bem coordenados e objetivos, que têm hábitos, que "sabem como fazer"” (MAUSS, 2003 p. 411). Para ele "a criança, como o adulto, imita atos bem-sucedidos que ela viu ser efetuados por pessoas nas quais confia e que têm autoridade sobre ela" (MAUSS, 2003 p. 405).

Aqui é possível perceber uma relação direta com o ensino de um ofício pelo adestramento, que propõe montagens fisio-psico-sociológica da série de atos; e impostas pela autoridade social (o professor). A imitação e repetição do imposto é a proposta para o aprendizado e a experiência. O erro e a repetição do fazer são para Sennett (2009) os alicerces do aprendizado do trabalho manual. A insistência nos erros promove não só a descoberta de soluções como favorece a capacidade de ensinar. Bosi (1999), quando trata do reavivamento de lembranças e de experiências adquiridas, utiliza o indivíduo artesão com exemplo do aprendizado contínuo: “o artesão acumulava experiência e os anos o aproximava da perfeição; era um mestre de ofício" (BOSI, 1999, p.88).

Ainda que Mauss (2003) não proponha esse método, ele constata que é utilizado em todas as sociedades. Embora na ideia possa incidir semelhanças, ela se difere do "bom adestramento" ponderado por Foucault (2008) sobre o poder disciplinar da vigilância, de 
sanções e punições. O entendimento de adestramento que aqui se procura conceituar é o imitar e o repetir até que a técnica (corporal ou instrumental) se mostre adequada à realização de atividades-fim.

Um dos casos estudados (experiências docentes) trata do ensino da Luteria na universidade. Por Luteria entende-se a atividade de construção e manutenção artesanal de instrumentos de cordas, que remonta documentadamente à primeira metade do segundo milênio, originada, em sua etimologia, da construção artesanal de alaúdes - luth em francês. O conjunto de técnicas desenvolvidas neste trabalho difundiu-se através da tradicional relação mestre/aprendiz, associação que diz respeito ao modo de aprender e fazer adotados em pequenas oficinas, em momentos históricos antes da energia elétrica, ou mesmo a vapor, e de exclusivo trabalho manual, pregando a qualidade de um instrumento ao vínculo direto entre o talento e a habilidade do artesão. Este tipo de transmissão de conhecimento, segundo Rugiu (1998) estrutura a principal forma de ensino de ofícios manuais.

Outro caso abordado é do ensino da modelagem de roupas no curso de Design de Moda. Moldes são como documentos que descrevem uma peça de roupa, revelando sua estrutura, afirma Nakamichi (2012). A modelagem possui papel importante no desenvolvimento da vestimenta, tendo como característica a capacidade de transportar o tecido do bidimensional para o tridimensional. Foi no período paleolítico que surgiram as primeiras manifestações de modelagem, a intenção das primeiras vestes era de proteger o corpo, Laver (1996) afirma que a descoberta do curtimento das peles e da agulha de ossos, permitiram que as peles fossem cortadas e moldadas no corpo, tornando possível costurá-las. No período neolítico, a manufatura de tecidos naturais como linho, lã, algodão e cânhamo, permitiram a existência de tecidos retangulares e triangulares, os quais eram modelados diretamente no corpo, presos por broches, cordões, faixas, criando formas drapeadas, as quais nos recordamos em serem utilizadas principalmente pelos romanos, gregos e egípcios. Com a evolução dos tecidos, a invenção da tesoura, fita métrica, manequim e máquina de costura, o ser humano foi sentindo cada vez mais necessidade de conforto e melhor assentamento do tecido no corpo. No Oriente a técnica de corte era aprimorada, e foi no período das cruzadas (século XI) que no Ocidente surgiram artesãos responsáveis pela confecção das roupas, bordados, estamparia, etc., os quais atendiam às classes mais elevadas.

A difusão de diferentes técnicas de modelagem também está relacionada à evolução dos tecidos tecnológicos e as demandas do consumidor contemporâneo. Por mais que nos dias 
atuais exista uma infinidade de máquinas e processos automatizados, a construção de moldes ainda hoje se constitui massivamente de procedimentos artesanais, que em muito dependem do desenvolvimento de conhecimentos tácitos por parte do estudante, constituindo um constante desafio para o docente.

Existe ainda, para as duas aproximações empíricas citadas (a luteria e a modelagem de roupas), o autodidatismo. Ao contrário da instrução formal, também se constitui um espaço na construção destes profissionais. O conhecimento adquirido por autodidatas é recebido pela experiência individual, pelo método empírico, através de estudos de modelos existentes e elaboração de técnicas específicas e exclusivas e vai se beneficiar pelo contato as duas abordagens teóricas estudadas. Para Silva (2012), a relação do ser humano com o aprendizado sozinho, é inerente à capacidade humana de aprender, e sugere que todos os indivíduos experimentam de alguma forma certo autodidatismo. Silva (2012) também pondera que o autodidatismo "tanto pode ser uma estratégia de sobrevivência quanto uma atitude de resistência à dominação", o que colabora de certa forma, com um inicial estranhamento dos ofícios estarem em ambiente acadêmico perante os profissionais autodidatas.

O percurso metodológico utilizado consiste na apresentação e entendimento das abordagens: behaviorista, em duas fases (clássica de Pavlov e contemporânea de Skinner) e pedagogias alternativas escolanovistas, no âmbito do século XX, essencialmente pelo ponto de vista do construtivismo Freinetiano, e tentativa de relacioná-las com o adestramento proposto e a livre-experimentação, em articulação com as experiências dos autores em de sala de aula.

Abaixo estão apresentadas as conceituações sobre as abordagens pedagógicas estudadas e seus vínculos (possíveis) com a prática do ensino de um ofício em sala de aula.

\section{Behaviorismo}

A conceituação de behaviorismo, originada do termo inglês behavior (comportamento ou conduta) parte do campo da psicologia e da separação científica do que pode ou não ser observado e quantificado e, posteriormente, sistematizado. Giusta (1985) considera que "a meta do behaviorismo sempre foi a construção de uma psicologia "científica"” (GIUSTA, 1985).

Pelos estudos de Pavlov (1849-1936), médico e fisiologista russo, se fundamentou o behaviorismo clássico (ou respondente) e diz respeito à relação estímulo-resposta, na qual um 
estímulo antecedente gera uma resposta consequente. Para Giusta (1985), se iniciou pela “observação de respostas incondicionadas a estímulos incondicionados, mas o interesse central se firma na obtenção de uma determinada resposta, provocada por um estímulo previamente neutro, quando este é associado a um estimulo incondicionado" (GIUSTA, 1985 p. 23). Ou seja, algumas respostas são incondicionadas, inatas; mas outras podem ser aprendidas, por meio de estímulos (agradáveis ou não). Firmou-se assim um modelo que objetivava controlar o comportamento, onde esse comportamento é sempre uma resposta criada. Considerava-se inclusive que a profissão e o caráter poderiam ser definidos por estímulos adequados e específicos.

Nos final dos anos 1950, o psicólogo norte-americano Skinner (1904-1990) sugere uma alteração que se proponha a manter ou extinguir algum comportamento objetivado. A partir dessas diretrizes ele desenvolveu o chamado condicionamento operante, considerado por Giusta (1985) uma superação do condicionamento pavloviano. Skinner ocupou-se em relacionar o comportamento a ser aprendido e as suas conseqüências, ou seja, os indivíduos respondem de formas variadas aos estímulos recebidos e, dependendo da relevância da resposta para o que se pretende ensinar, será ou não mantida. Para isso utiliza-se de incentivos para que o comportamento se mantenha ou se extinga.

Juntamente com o condicionamento operante, Skinner também embasou assim a concepção pedagógica do behaviorismo, uma vez que identificava a aprendizagem como condicionamento (NEVES e DAMIANI, 2006). Como, para Skinner, o fator mais importante nesse modelo de condicionamento não são os estímulos que antecedem às respostas e sim os que as reforçam, existe grande preocupação em sempre que o aluno acertar uma resposta, haver o reforço deste acerto. O aluno é "ensinado" na medida em que é induzido a se engajar em novas formas de comportamento e em formas específicas em situações específicas. Para o behaviorismo ensinar significa transmitir conhecimento. A próxima etapa só é alcançada (estímulo positivo) quando a anterior é realizada com sucesso (resposta positiva).

Os adeptos desta teoria de reforço o consideraram capaz de explicar a aquisição de comportamentos voluntários de todos os tipos e por isso a aprendizagem é vista como "mudança de comportamento resultante do treino ou da experiência" (GIUSTA, 1985), que na realidade deste texto é chamada de adestramento. Acredita-se que o processo de aprendizagem é fruto de memorizações provenientes de repetições de ações realizadas pelos estudantes (BARROS e CAVALCANTE, 1999). 
Segundo Vasconcelos, Praia e Almeida (2003) a concepção behaviorista de aprendizagem considera o aluno passivo e reprodutor instruções, ficando ausente do desenvolvimento de sua criatividade, curiosidade e motivação. Para estes autores, o aluno pode se tornar apático, devido à excessiva dependência do professor. Neves e Damiani (2006) consideram que ações pedagógicas assentadas nesta concepção empirista de aprendizagem emudecem os alunos, uma vez que os submete somente à autoridade do saber dos professores, dos livros e das instruções programadas. Todo o conhecimento está fora do sujeito, portanto, no professor e nos livros. O aluno é um recipiente vazio onde é necessário "despejar" o conhecimento (DARSIE, 1999). A valorização do aluno como transformador destas informações não aparece suficientemente representada nesta abordagem (VASCONCELOS, PRAIA e ALMEIDA, 2003).

\section{Nova escola}

A Nova Escola é uma corrente pedagógica anti-conservadora, que tinha entre seus protagonistas o educador francês Célestin Freinet. Buscava seguir outro caminho além das práticas impostas pela tradicional linha de ensino predominante no início do século $\mathrm{XX}$. Freinet propôs uma nova abordagem onde o aluno desempenha o papel principal na sala de aula. De caráter experimental, suas aulas tinham como interesse principal a forma como o pensamento individual de cada aluno interpreta o mundo em que vivemos. Esta visão se opunha veementemente às noções de hierarquia e adestramento que eram adotadas nos ambientes tradicionais de ensino, sendo considerada até mesmo anarquista. $\mathrm{O}$ educador, assim como outros simpatizantes do movimento construtivista, não gostava que chamassem a sua abordagem como método, ao invés disso, ele preferia que chamasse apenas de técnicas de Freinet (FREINET, 1966). Segundo o pedagogo, a função educativa não está de modo algum confinada às paredes da escola. Pensando neste aspecto, propôs a realização de uma aula prática, levando os alunos para uma experiência fora da sala de aula, dando início as "aulas passeio", ou como atualmente conhecemos de "estudos de campo". Desta forma, percebeu que as crianças estavam mais entusiasmadas do que antes e voltavam para a sala de aula com pensamentos lúdicos. Em seguida, propôs transformar estes pensamentos lúdicos em redações, que posteriormente foram impressas pelos próprios alunos em uma impressora tipográfica, destas em que se encaixam letra por letra para formar uma matriz. As redações eram então enviadas para outro colégio, em outra cidade, fazendo com que os alunos ficassem 
totalmente envolvidos e engajados, tornando assim o ambiente escolar e a experiência de ensino mais dinâmica e agradável, pois além da correspondência interescolar, os textos eram publicados e lidos pelos colegas de classe. Freinet acreditava que a voz do professor não é a mais importante e considerava a explicação exaustiva como o inimigo número um da boa aprendizagem.

O educador criou em 1957 a Federação Internacional de Movimentos da Escola Moderna que congrega milhares de educadores de todos os continentes e realiza encontro bianuais em diferentes países do mundo (OLIVEIRA, 2005). Seus métodos de ensino são amplamente utilizados até os dias de hoje.

\section{Perspectivas orientadas pela prática}

Com a apresentação das concepções de ensino/aprendizagem sugeridas, busca-se aqui averiguar sua localização no ensino da prática de um ofício. Pela experiência dos autores, as abordagens citadas se materializam, juntas, na necessidade de se alcançar alguns objetivos em sala de aula, imprescindíveis para o aprendizado que propõem.

Na prática se constata que, por exemplo, pular etapas e caminhar (ou tentar caminhar) para o livre experimentalismo precocemente compromete não só a qualidade do trabalho, mas corrompe o aprendizado. A atenção aos princípios básicos dos métodos tradicionais agregam uma visão do processo como um todo, da mesma forma com que esforços em um item e desconsideração do projeto completo, não alcançam as concepções mais básicas da criação e produção. Esses fatos se dão claramente pelo desprezo dos alunos pela utilização dos instrumentos manuais em detrimento às máquinas e não cumprimento de todas as etapas básicas. Sennett (2009) comenta sobre a repetição e a prática que "é perfeitamente característico da abordagem do artífice. Ao mesmo tempo pensar e fazer. Fazer, refazer e fazer mais uma vez" (SENNETT, 2009 p. 52).

Corrobora-se aqui pela utilização de métodos atrelados ao behaviorismo com busca de instituir a compreensão da tradição e do todo antes da criação. Por outro lado, os autores concordam que apenas uma abordagem autoritária e castradora da criatividade não permite a expansão do conhecimento e seu total entendimento. Para isso considera-se a importância, sequencialmente, da liberdade à experimentação e inovação, que acontece de forma mais madura e concreta quando a base está fundamentada. 
Por todo o exposto, se propõe a utilização mesclada das abordagens descritas no ensino de um ofício em ambiente acadêmico, com conteúdo metricamente sistematizado pelo docente e impositivo até que se consolide os alicerces para a compreensão da prática. E sim, a partir de então, a livre experimentação pode acontecer, tendo o aluno e suas particularidades como centro da relação quem ensina/quem aprende.

Sugere-se assim que, no processo de transmissão de conhecimentos tácitos - como o ensino de um ofício, a metodologia encare o "adestramento" e o experimentalismo como etapas na construção de uma formação acadêmica ampla. Substitui-se assim o mero oposicionismo por uma linha de pensamento agregadora, capaz de observar o que há de mais interessante em cada uma das abordagens mostradas e colocar suas práticas a serviço de uma experiência de ensino ao mesmo tempo consistente e estimulante.

Conclui-se no entendimento que, sendo o termo ofício definidor de uma atividade que não é aprendida formalmente, mas que se aprende, não se pode excluir deste processo a curiosidade, a investigação e o aprendizado pelas incertezas (SENNETT, 2009), mas sempre embasado pelo conhecimento que já existe conceituado.

\title{
Reflections on teaching a craft
}

\begin{abstract}
The aim of this study is to reflect on the essentially practical disciplines in the university environment education, investigating links with some pedagogical approaches and at the same time drawing a parallel with existing training practices and experimentation in the method used by the authors in room class. It was concluded that despite the apparent opposition between the approaches in the theoretical realm, the practice they are is perceived like additional, making them actually steps, which also appears necessary to build a complete academic education.
\end{abstract}

Keywords: Teaching; Learning; Craft; behaviorism; New school 


\section{REFERÊNCIAS BIBLIOGRÁFICAS}

BARROS, Simone e CAVALCANTE, Patrícia Smith. Os recursos computacionais e suas possibilidades de aplicação no ensino segundo as abordagens de ensino aprendizagem. Anais do Workshop Internacional Sobre Educação Virtual: Realidade e desafios para o próximo milênio. Fortaleza: UECE, 1999.

DARSIE, Marta Maria Pontin. Perspectivas Epistemológicas e suas Implicações no Processo de Ensino e de Aprendizagem. Uniciências, Cuiabá, v3, n.1, 1999.

DUBAR, Claude. A socialização: construção das identidades sociais e profissionais. Trad. Andréa Stabel M. da Silva. São Paulo: Martins Fontes, 2005.

FREINET, Célestin. Para uma escola do povo. São Paulo: Martins Fontes, 1966.

FREINET, Célestin. As técnicas Freinet da escola moderna. Editorial Estampa, lda, 1976. FOUCAULT, Michel. Vigiar e punir: nascimento da prisão. Trad. Raquel Ramalhete. Petrópolis, RJ: Vozes, 2008.

GIUSTA, Agnela da Silva. Concepções de aprendizagem e práticas pedagógicas. Educação em Revista, Belo Horizonte, n. 1, p. 25-31, 1985.

LAVER, James. A roupa e a moda: uma história concisa. São Paulo: Cia. Das Letras, 1996.

MAUSS, Marcel. As técnicas do corpo. In: Sociologia e Antropologia. São Paulo: Cosac Naify, 2003.

NAKAMICHI, Tomoko. Pattern magic 2: a magia da modelagem. São Paulo: Gustavo Gili, 2012.

NEVES, Rita de Araújo e DAMIANI, Magda Floriana. Vygotsky e as teorias da aprendizagem. Unirevista, São Leopoldo, v.1, n.2, 2006.

OLIVEIRA, Magda Sarat. Fundamentos filosóficos da educação infantil. Maringá: EDUEM, 2005.

SOUSA NETO, Manoel Fernandes. O ofício, a oficina e a profissão: reflexões sobre o lugar social do professor. Cadernos Cedes. Campinas, v. 25, n. 66, p. 249-259, maio/ago. 2005

VASCONCELOS, Clara, PRAIA, João Félix e ALMEIDA, Leandro. Teorias de aprendizagem e o ensino/aprendizagem das ciências: da instrução à aprendizagem.

Psicologia Escolar e Educacional, Campinas, v.7, n. 1, 2003. 